\title{
AGRICULTURA URBANA E PERIURBANA: POTENCIALIDADES E LIMITAÇÕES PARA O DESENVOLVIMENTO DO MUNICÍPIO DE BENEVIDES (PA)
}

\author{
Glenda Maria Braga Abud* \\ Maria Lúcia Bahia Lopes** \\ Rosália do Socorro Silva Corrêa*** \\ Ruth Helena Cristo Almeida****
}

RESUMO: O cultivo de flores e plantas ornamentais é uma atividade geradora de empregos e de baixo impacto ambiental. Essas características decorrem da baixa mecanização e reduzida utilização de agrotóxicos. Caracterizada por ser praticada na forma de agricultura periurbana, pela dependência dos centros de consumo, ela pode ser uma estratégia para a promoção do desenvolvimento local. Nesse contexto, esta pesquisa teve como objetivo analisar a produção de flores e plantas ornamentais no município de Benevides, no Estado do Pará, para identificar sua contribuição para o desenvolvimento local. Para tanto, foi feita uma survey descritiva na forma de censo com 25 produtores do município. Foram pesquisadas três dimensões do desenvolvimento local: econômica, social e ambiental. Os resultados mostraram uma atividade essencialmente de subsistência, com baixa articulação entre os produtores e limitações de ordem tecnológica e produtiva, aspectos que resultaram em restrita capacidade de contribuir para o desenvolvimento no município estudado.

PALAVRAS-CHAVE: Agricultura periurbana; Desenvolvimento local; Floricultura; Produção familiar; Sustentabilidade.

\section{URBAN AND PERI-URBAN AGRICULTURE: POTENTIALITY AND LIMITATIONS FOR THE DEVELOPMENT OF BENEVIDES, BRAZIL}

ABSTRACT: The cultivation of flowers and ornamental plants generates employment and has low environmental impact. These characteristics are due to

\footnotetext{
* Mestre em Desenvolvimento e Meio Ambiente Urbano pela Universidade da Amazônia - Unama, Brasil. E-mail: glenda.abud@gmail.com

**:Doutorado em Economia Aplicada pela Universidade Federal de Viçosa - UFV, Brasil.

*** Doutorado em Sociologia pela Universidade Federal da Paraíba - UFPB, Brasil.

***** Doutorado em Ciências Agrárias pela Universidade Federal Rural da Amazônia - UFRA, Brasil.
} 
low mechanization and reduced used of fertilizing agents. Since it is characterized as peri-urban agricultural activity due to its dependence on consumption centers, it may be a strategy for the promotion of local development. Current paper analyzes the production of flowers and ornamental plants in the municipality of Benevides PA Brazil, to identify its contribution towards local development. A descriptive survey or census was undertaken with 25 producers in the municipality. The economic, social and environmental dimensions were researched. Results showed an essentially subsistence activity, with low articulation between producers and limitation in technology and productivity. They are aspects that restrict their capacity in the development of the municipality analyzed.

KEY WORDS: Peri-urban agriculture; Local development; Flower culture; Familial production; Sustainability.

\section{INTRODUÇÃO}

As exportações brasileiras de flores e plantas ornamentais têm perdido mercado de forma acelerada. Segundo dados da Secretaria de Comércio Exterior (SECEX), do Ministério do Desenvolvimento, Indústria e Comércio (MDIC), apresentados no Seminário de Comércio Exterior sobre Flores 2017, no período de 2005 até 2016, as exportações brasileiras tiveram redução de 52,4\% e, quando a análise se concentra somente no ano de 2016, essa redução alcança 21,1\% (CONFEDERAÇÃO DA AGRICULTURA E PECUÁRIA DO BRASIL, 2017).

Os principais mercados internacionais para flores e plantas ornamentais do Brasil são os Países Baixos (Holanda), com 47,5\% das exportações, Estados Unidos da América do Norte, com 18,3\%, e Itália, com 13,0\%. Esses três destinos representam $78,8 \%$ do total das exportações brasileiras (CONFEDERAÇÃO DA AGRICULTURA E PECUÁRIA DO BRASIL, 2017). Quanto aos Estados exportadores, destacam-se São Paulo, com 60,1\% das exportações nacionais, Rio Grande do Sul, com 12,3\%, Ceará, com 10,3\%, e Minas Gerais, com 9,3\%. Desta forma, observa-se que 82,7\% das exportações estão concentradas em quatro Estados do Brasil. Nesse cenário, o Estado do Pará ocupa a quinta posição no mercado de exportação de flores e plantas ornamentais; no ano de 2013, o setor movimentou US\$ (FOB) 182.222,00, o que representou apenas $0,77 \%$ das exportações brasileiras no período (CONFEDERAÇÃO DA AGRICULTURA E PECUÁRIA DO BRASIL, 2017). 
Nesse contexto, apesar do cenário internacional negativo para as exportações brasileiras, a cadeia de produção de flores e plantas ornamentais, como destaca o Sebrae (2017, p. 62), "[...] é essencialmente focada no próprio mercado interno"; em complemento, o Instituto Brasileiro de Floricultura (IBRAFLOR) destaca que, na última década, o setor de floricultura cresceu em média de 8 a 10\% ao ano, mesmo enfrentando dificuldades na economia (INSTITUTO BRASILEIRO DE FLORICULTURA, 2017). Observa-se, assim, que a cadeia de produção de flores e plantas ornamentais tem encontrado no mercado interno expressivas oportunidades de crescimento.

Nesse contexto, a presente pesquisa tem por objetivo analisar a produção de flores e plantas ornamentais no Estado do Pará, especificamente no município de Benevides, fundamentada teoricamente na agricultura exercida na forma periurbana, segundo sua capacidade de contribuir para a inclusão socioprodutiva e a promoção da qualidade de vida entre pequenos produtores, localizados no entorno da cidade de Belém do Pará, de tal forma a contribuir para o desenvolvimento local.

Aprofundar a compreensão dessa atividade encontra alicerce na necessidade de promover a emancipação social, pela formação de renda que, em última instância, resulta no fortalecimento de práticas que contribuem para o desenvolvimento, especialmente pelo enfrentamento da pobreza e pela redução da vulnerabilidade de pequenos produtores. Nessa perspectiva, o desenvolvimento local pode ser conceituado, conforme Buarque (2008, p. 25), como "um processo endógeno de mudança, que leva ao dinamismo econômico e à melhoria da qualidade de vida da população em pequenas unidades territoriais e agrupamentos humanos".

\subsection{AGRICULTURA URBANA E PERIURBANA: NA PERSPECTIVA TEÓRICA}

Diversos pesquisadores têm concentrado esforços em compreender as possibilidades e limitações da agricultura sob diferentes perspectivas, que incluem segurança alimentar (SANTOS, 2011), êxodo rural (VINHOLI; MARTINS, 2012), agroecologia (RIBEIRO et al., 2012), redução da pobreza (PESSÔA, 2005), fixação dos jovens nas áreas rurais (TROIAN et al., 2011), política social e de desenvolvimento urbano (COUTINHO; COSTA, 2011; SILVA et al., 2013), educação ambiental (FREITAS 
et al., 2013), desenvolvimento local (GHISLENI, 2012), entre outros.

Monteiro e Monteiro (2006, p. 52) destacam que a agricultura familiar reúne um amplo conjunto de produtores, compreendendo desde aqueles que praticam agricultura de subsistência a aqueles que se caracterizam por modelos empresariais e capitalistas de produção. Contudo, todos eles têm em comum a prevalência da organização familiar, seja na realização do trabalho em si, seja na gestão das unidades de produção. Os mesmos autores reforçam a participação da agricultura familiar como fornecedora de alimentos e evidenciam fortemente "[...] a magnitude deste tipo de atividade e suas possibilidades na promoção de um desenvolvimento local, com a melhoria da qualidade de vida [...]".

Quanto à dimensão urbana e periurbana da agricultura, observa-se que questões como o avanço da urbanização, a progressiva incorporação de aportes tecnológicos, muitos deles caros e inacessíveis para pequenos produtores, e a expansão da agricultura em larga escala acabaram por desencadear um processo de exclusão, que levou boa parte desses pequenos produtores a migrar para as cidades e trazer consigo a experiência de produção agropecuária. Nessa perspectiva, a agricultura urbana e periurbana desenvolvida com base na experiência da produção rural e no aproveitamento de espaços urbanos é uma alternativa para a diminuição da pobreza, especialmente pela capacidade de geração de renda e de aproveitamento ambiental de forma mais sustentável (MADALENO, 2001).

No Brasil, a agricultura urbana e periurbana vêm, progressivamente, ganhando destaque, especialmente por sua capacidade privilegiada de resgatar a cidadania, pelos aspectos relacionados com a sustentabilidade econômica e ambiental e pela possibilidade de valorização da cultura rural. Observa-se que ainda existe elevada escassez de dados quanto a essas atividades no Brasil, especialmente quando a agricultura ocorre no interior das cidades. Esse aspecto impacta negativamente na capacidade de formulação de políticas públicas destinadas a essa forma de produção (NEVES; PINTO, 2015).

Mougeot (2000) já destacava que a agricultura urbana se caracteriza por sua localização e poderia ser dividida em: (1) agricultura intraurbana ou urbana, quando ela é feita dentro das cidades; ou (2) periurbana, quando ela ocorre no entorno das cidades. $\mathrm{O}$ autor destaca ainda que utilizar apenas este critério desperta 
muita polêmica entre os pesquisadores, uma vez que se baseia apenas no critério urbano e rural e, assim, fundamenta-se em linhas teóricas muito tênues. Desta forma, para superar essa limitação, surgiram diversas perspectivas teóricas utilizadas para diferenciar as atividades agrícolas feitas nas cidades e em seu entorno. Para solucionar e esclarecer esse aspecto, Mougeot (2000) evidencia a necessidade de diferenciar, além da localização espacial, questões relacionadas ao: (1) tipo de atividade econômica, (2) sistema e escala de produção, (3) categorias e subcategorias de produtos (alimentícios e não alimentícios) e (4) destinação dos produtos finais, incluindo suas formas de comercialização, entre outros.

\subsection{TEORIA DO DESENVOLVIMENTO}

Conforme Vázquez Barquero (2000), os mais recentes paradigmas do desenvolvimento culminaram com a Teoria do Desenvolvimento Endógeno, segundo a qual as melhorias decorrentes das inovações proporcionadas por novas tecnologias, melhor qualificação dos recursos humanos e aprimoramento da infraestrutura local gerariam efeitos positivos que se refletiriam como forças motrizes para o desenvolvimento e, quando esses aprimoramentos se espalhassem pelo entorno, beneficiariam não apenas seus desenvolvedores, mas também um amplo conjunto de agentes econômicos, que incluem desde os concorrentes até produtores de outros setores. Essa capacidade de se espalhar pela economia na localidade, por meio de transbordamentos, e multiplicar resultados benéficos, foi designada de spillover effects. Ademais, como a tecnologia e outros elementos que não eram considerados pelos modelos clássicos de desenvolvimento, pois eram considerados exógenos ao modelo, passaram a ser internalizados pela Teoria do Desenvolvimento Endógeno.

Outro aspecto de destaque para o desenvolvimento endógeno é a competição entre os agentes econômicos, visto que, para manter ou ampliar suas participações de mercados, os agentes que atuam em mercados competitivos na forma de concorrentes estão permanentemente promovendo melhorias nos produtos, ou nos processos de produção, com o intuito de maximizar suas vendas, lucratividade e participações de mercado. 
Destarte, essas inovações assumem um efeito multiplicador para o desenvolvimento, uma vez que, ao se espalharem pela economia em decorrência da dificuldade de serem protegidas por seus criadores, seriam copiadas por outros agentes econômicos, promovendo, assim, a incorporação da evolução tecnológica por terceiros, aumentando a capacitação do capital humano, contribuindo para o crescimento econômico na região (VÁZQUEZ-BARQUERO, 2000). Kronemberger (2011, p. 33) complementa e destaca que o desenvolvimento local é essencialmente "[...] um processo endógeno de mudanças [...] no sentido de ser conduzido por atores locais (instâncias de governos, empresas, organizações da sociedade civil, universidades e outros) aproveitando as potencialidades locais para fazer acontecer". A autora reforça que

O desenvolvimento local é um produto do conhecimento e do aproveitamento das potencialidades, oportunidades e vantagens comparativas da localidade, que resultam do desenvolvimento simultâneo dos capitais humano, social e produtivo, bem como do uso sustentável do capital natural (KRONEMBERGER, 2011, p. 31).

Martinelli e Joyal (2004) esclarecem e complementam que a compreensão do desenvolvimento local pode ocorrer sob diferentes pontos de vista, incluindo a dimensão econômica e competitiva, mas também como uma forma de manter a identidade em determinado espaço geográfico frente a uma sociedade globalizada. Para esses autores, a perspectiva local assume a dimensão de um distrito, uma localidade, um município, mas também pode ser um país, uma região do planeta. Assim, eles reforçam que a perspectiva local não deve ser compreendida como um sinônimo de pequeno, uma vez que não se refere necessariamente a uma redução.

O desenvolvimento local constitui-se, portanto, em um conjunto de ações coordenadas entre agentes econômicos, na perspectiva horizontal, e entre os governos e os agentes econômicos, na perspectiva vertical, e, em uma perspectiva ampla, contempla ações destacadas por Kronemberger (2011) como: (1) identificar ou incentivar as vocações locais; (2) descobrir e mobilizar potencialidades típicas da região; (3) atuar de forma sustentável quanto aos recursos naturais; (4) mobilizar 
e integrar a comunidade para ações de desenvolvimento; (5) envolver parceiros para a realização de projetos; (6) fortalecer os laços de confiança, ajuda mútua e organização da sociedade em face dos interesses convergentes; (7) aprimorar e desenvolver cadeias de produção e atuar para fortalecer redes de cooperação sociais e econômicas como forma de criar riqueza, ampliar as ofertas de empregos, atrair investimentos e fomentar novos empreendimentos; (8) incentivar o fortalecimento de uma cultura empreendedora; (9) fortalecer a competitividade da economia regional, concentrando-se nas capacidades locais, como forma de diminuir a dependência externa e para aumentar a capacidade de enfrentar concorrentes externos; e (10) modernizar a gestão pública, incentivar a formação de parcerias, a democracia, a delegação, ampliar os mecanismos de controle social, a transparência, preservando as finanças públicas, direcionando as ações para as demandas da sociedade.

Ao considerar esses aspectos, evidencia-se a amplitude do desenvolvimento para a promoção da qualidade de vida na sociedade moderna e se reforça a necessidade de estabelecer mecanismos eficientes para identificar o desenvolvimento, uma vez que, com base nesses elementos, é possível formular ações para seu aprimoramento, mostrando essa necessidade, a relevância das dimensões de análise para acompanhar e promover o desenvolvimento local.

\section{MATERIAIS E MÉTODOS}

Os procedimentos metodológicos utilizados neste estudo caracterizam, conforme Gil (2014), um survey exploratório e descritivo, feito na forma de censo, com a utilização de questionário de pesquisa aplicado aos produtores de flores e plantas ornamentais. O local da pesquisa foi o município de Benevides, Estado do Pará, localizado na Região Metropolitana de Belém, Figura 1, situado a 33 quilômetros da cidade de Belém do Pará, capital do Estado. A cidade de Benevides está posicionada geograficamente a $01^{\circ} 21^{\prime} 41^{\prime \prime}$ de latitude Sul e $48^{\circ} 14^{\prime} 41^{\prime \prime}$ de longitude Oeste, tendo 28 metros de altitude média (IBGE, 2017). A origem do município é eminentemente agrícola, tendo sido criado em 1961 por desmembramento do município vizinho de Ananindeua, mas os primeiros registros históricos do município datam de 1878, ocasião em que ele deixou de ser uma colônia agrícola (IBGE, 2017). 


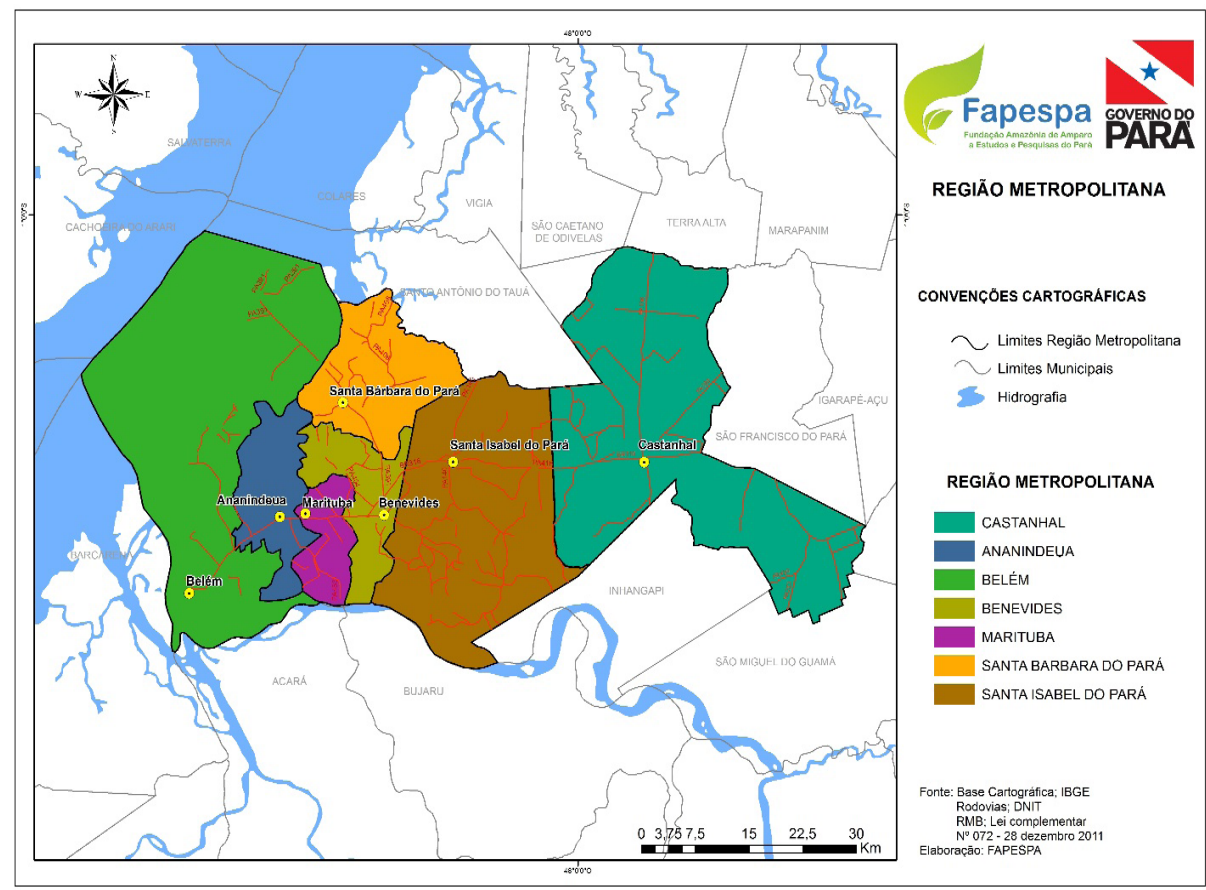

Figura 1. Mapa da Região Metropolitana de Belém do Pará Fonte: Governo do Estado do Pará (2017).

O solo predominante no município é o Latossolo Amarelo, com vegetação de floresta secundária, decorrente da recomposição da mata nativa, que, originalmente, foi desmatada para a exploração agrícola e pecuária. O clima na região é úmido com temperaturas elevadas durante todo o ano. A região é bem servida de água, proveniente, principalmente, dos grandes rios e do elevado índice pluviométrico, que supera os $2.500 \mathrm{~mm} / \mathrm{ano}$, com período chuvoso concentrado nos meses de janeiro a junho, e umidade relativa do ar em média de 85\% (GOVERNO DO ESTADO DO PARÁ, 2016).

A área do município é de $187,83 \mathrm{~km}^{2}$ e a população, segundo o censo populacional do Instituto Brasileiro de Geografia e Estatística (IBGE) de 2010, alcançou 51.651 habitantes, bem distribuídos entre a área urbana e rural, com leve prevalência da área urbana, que conta com 28.912 (55,97\%) habitantes, superando os 22.739 (44,02\%) residentes da área rural (IBGE, 2010). A economia do município 
é baseada principalmente no comércio e na indústria de transformação (GOVERNO DO ESTADO DO PARÁ, 2017).

Junqueira e Peetz (2006) destacam que a floricultura paraense se concentra em sete municípios da Mesorregião Metropolitana de Belém, que, juntos, alcançam 91\% da produção estadual, sendo Benevides o principal produtor paraense, com $36 \%$ do total produzido no Estado. Os quantitativos do setor colocam o Estado do Pará na décima terceira posição no mercado interno, quando o critério utilizado é a produção total (INSTITUTO BRASILEIRO DE FLORICULTURA, 2017).

O trabalho de campo foi iniciado pela identificação e localização dos produtores de flores e plantas ornamentais no município. Para tal, foram consultadas a Empresa de Assistência Técnica e Extensão Rural do Estado do Pará (EMATER) e a Secretaria de Estado de Desenvolvimento Pecuário e da Pesca (SEDAP), tendo complementado a base de dados informaçóes obtidas na prefeitura municipal e junto a agrônomos no município. Foram localizados 28 produtores ativos, todos foram convidados a participar da pesquisa, mas dois produtores se recusaram, tendo sido obtidos 26 questionários de pesquisa válidos.

O instrumento de coleta de dados utilizado na investigação foi o questionário, organizado em duas seções. A primeira reuniu informações socioeconômicas dos produtores, compreendendo aspectos como idade, escolaridade, composição familiar, renda, número de trabalhadores nas propriedades, entre outros. As respostas dessa seção foram elaboradas na forma dicotômica e de múltipla escolha. A segunda seção do questionário versou sobre a contribuição da atividade para o desenvolvimento e foi dividida em três subseções, que envolveram aspectos (1) econômicos, (2) sociais e (3) ambientais. As questões foram elaboradas na forma de assertivas com respostas em escala de Likert, com sete opçóes: 1 para discordo totalmente; 2 para discordo muito; 3 para discordo pouco; 4 para não discordo nem concordo; 5 para concordo pouco; 6 para concordo muito; e 7 para concordo totalmente. Após o levantamento, os dados foram tratados com estatística descritiva, como mostrado em Silvestre (2007) e sistematizados em tabelas. 


\section{RESULTADOS E DISCUSSÕES}

\subsection{PERFIL DOS ENTREVISTADOS}

Os resultados da investigação mostraram que a produção de flores e plantas ornamentais no município de Benevides (PA) (Tabela 1) é uma atividade predominantemente masculina (65\%), caracterizada por produtores na faixa etária de 41 a 60 anos (57\%), que moram nas propriedades rurais (65\%) e residem com até três pessoas (54\%), pais, na maioria dos casos, $92 \%$. Os produtores têm renda de até $\mathrm{R} \$ 1.874,00$ mensais (69\%), sendo a produção de flores e plantas ornamentais importante para a renda familiar, com participação de até 60\% (54\%) na maior parte das famílias, porém alcançando mais de 90\% em parcela expressiva (23\%) dos entrevistados. Com escolaridade intermediária, esses produtores cursaram o ensino médio completo (27\%) e contam para a produção, em média, com dois trabalhadores familiares, dois contratados e um temporário, quando há necessidade de reforço na produção.

Tabela 1. Perfil socioeconômico dos produtores de flores e plantas ornamentais no município de Benevides (PA)

(Continua)

\begin{tabular}{l|l|c|c}
\hline & & Frequência & Percentual \\
\hline \multirow{3}{*}{ Sexo } & Masculino & 17 & 65 \\
\cline { 2 - 4 } & Feminino & 9 & 35 \\
\hline \multirow{5}{*}{ Idade (em anos de vida) } & 20 a 30 & 2 & 8 \\
\cline { 2 - 4 } & 31 a 40 & 1 & 4 \\
\cline { 2 - 4 } & 41 a 50 & 5 & 19 \\
\cline { 2 - 4 } & 51 a 60 & 2 & 38 \\
\cline { 2 - 4 } & 61 a 70 & 6 & 23 \\
\cline { 2 - 4 } & Mais de 70 & 2 & 82 \\
\hline \multirow{3}{*}{ Filhos } & Sim & & 8 \\
\cline { 2 - 4 } & Não & & 24 \\
\hline
\end{tabular}


Escolaridade

Número de pessoas na residência

Residem na propriedade

Renda familiar (em salários mínimos)

Participação da floricultura na renda (\%)

Tempo na atividade (em anos)

\begin{tabular}{|c|c|c|}
\hline & Frequência & Percentual \\
\hline Fundamental incompleto & 9 & 35 \\
\hline Fundamental completo & 1 & 4 \\
\hline Médio incompleto & 4 & 15 \\
\hline Médio completo & 7 & 27 \\
\hline Superior incompleto & 1 & 4 \\
\hline Superior completo & 3 & 12 \\
\hline Pós-graduado & 1 & 4 \\
\hline $1 \mathrm{a} 3$ & 14 & 54 \\
\hline $4 \mathrm{a} 6$ & 10 & 38 \\
\hline 7 a 9 & 2 & 8 \\
\hline Sim & 17 & 65 \\
\hline Não & 9 & 35 \\
\hline Até 2 & 18 & 69 \\
\hline 2 a 5 & 3 & 11 \\
\hline 5 a 8 & 1 & 4 \\
\hline 8 a 10 & 2 & 8 \\
\hline Maior que 10 & 2 & 8 \\
\hline $1 \mathrm{a} 10$ & 3 & 12 \\
\hline 11 a 20 & 2 & 8 \\
\hline 21 a 30 & 2 & 8 \\
\hline $31 \mathrm{a} 40$ & 1 & 4 \\
\hline 41 a 50 & 4 & 15 \\
\hline 51 a 60 & 2 & 8 \\
\hline 61 a 70 & 1 & 4 \\
\hline 71 a 80 & 0 & 0 \\
\hline 81 a 90 & 1 & 4 \\
\hline 91 a 100 & 5 & 19 \\
\hline Não sabe & 5 & 19 \\
\hline Até 5 & 4 & 15 \\
\hline 06 a 10 & 5 & 19 \\
\hline 11 a 20 & 7 & 27 \\
\hline Mais de 20 & 10 & 39 \\
\hline
\end{tabular}

Fonte: Pesquisa de campo (2018). 


\subsection{CONTRIBUIÇÃO DA FLORICULTURA PARA O DESENVOLVIMENTO LOCAL}

A contribuição da atividade para o desenvolvimento local foi analisada segundo três dimensões: econômica, social e ambiental. A dimensão econômica, conforme dados apresentados na Tabela 1 , revelou que os produtores reconhecem que sabem como obter lucro com a floricultura (E01; 6,23 $\pm 1,27)$, que estão atentos para novas espécies (E02; 6,12 $\pm 1,50)$ e novas tecnologias (E06; 5,19 $\pm 2,31)$ e que, por meio da atividade florística, puderam melhorar sua qualificação técnica e gerencial (E03; 6,08 \pm 1,55), aumentando, assim, o capital humano e melhorando, principalmente, a lucratividade (E04; 6,04 \pm 1,45) e, com menor intensidade, a produtividade (E09; 4,62 $\pm 2,82$ ) e a qualidade dos produtos (E07; 4,77 $\pm 2,48$ ), isso ocorreu mesmo sem utilizar equipamentos modernos (E12; $2,42 \pm 2,06)$.

Os entrevistados têm na produção de flores e plantas ornamentais uma atividade econômica importante para formação da renda familiar (E05; 5,85 $\pm 1,80)$ e mostram alguma segurança em contrair empréstimos para aplicar na atividade (E08; $4,73 \pm 2,32$ ) e entendem, em certa medida, que melhoraram de vida financeiramente (E10; 4,62 $\pm 1,96$ ) com a plantação de flores e plantas ornamentais. Os produtores percebem que o número de compradores e as vendas têm aumentado levemente com o tempo (E11; 4,35 $\pm 1,98)$, mesmo sem novos mercados (E13; 3,23 $\pm 2,10$ ). Contudo, ao responderem se estão acumulando patrimônio, eles se posicionam de forma neutra $(\mathrm{E} 12 ; 4,00 \pm 2,55)$, sugerindo que a floricultura no município é uma atividade predominantemente de subsistência e que não contribui para a diversificação de negócios (E14; 2,62 \pm 2,33).

Quanto à dimensão social, diante dos dados apresentados na Tabela 2, destacaram-se as médias baixas $(<4,00)$ para a maioria das alternativas investigadas. Desta forma, percebe-se que os produtores consideram a qualidade de vida prejudicada pela violência no município ( $S 01 ; 5,08 \pm 2,36)$, representando esse aspecto um limitador, pois a maioria dos negócios ocorre nas propriedades, normalmente com pagamento à vista em dinheiro; da mesma forma, os produtores manifestam preocupação com a continuidade da atividade, pois acreditam que os filhos preferem trabalhar nas cidades, em outras atividades não relacionadas com a agricultura (S02; 4,95 $\pm 2,50)$. 
Tabela 2. Aspectos econômicos da produção de flores e plantas ornamentais no município de Benevides (PA)

\begin{tabular}{|c|c|c|c|}
\hline Variáveis & & Média & $\begin{array}{l}\text { Desvio } \\
\text { Padrão }\end{array}$ \\
\hline Na floricultura sei como produzir para lucrar. & E01 & 6,23 & 1,27 \\
\hline Fico atento a novas espécies para incluí-las na produção. & E02 & 6,12 & 1,50 \\
\hline A floricultura financiou minha qualificação técnica e gerencial. & E03 & 6,08 & 1,55 \\
\hline $\begin{array}{l}\text { Aprimorei minhas formas de gerenciamento e assim melhorou meu } \\
\text { lucro. }\end{array}$ & E04 & 6,04 & 1,45 \\
\hline A atividade é importante para manutenção da renda familiar. & E05 & 5,85 & 1,80 \\
\hline Fico atento a novas tecnologias para utilizá-las na produção. & E06 & 5,19 & 2,31 \\
\hline Fiz inovações que possibilitaram ganhos de qualidade nos produtos. & E07 & 4,77 & 2,48 \\
\hline Tenho segurança em contrair financiamentos para aplicar na floricultura. & E08 & 4,73 & 2,32 \\
\hline $\begin{array}{l}\text { Fiz inovações que possibilitaram ganhos de produtividade com a } \\
\text { atividade. }\end{array}$ & E09 & 4,62 & 2,82 \\
\hline Com a floricultura, melhorei de vida (R\$). & E10 & 4,46 & 1,96 \\
\hline Tem crescido o número de compradores aumentando minhas vendas. & E11 & 4,35 & 1,98 \\
\hline Tenho acumulado patrimônio com a atividade florística. & E12 & 4,00 & 2,55 \\
\hline Busquei novos mercados para vender mais produtos. & E13 & 3,23 & 2,10 \\
\hline A renda da floricultura tem financiado outras atividades (diversificação). & E14 & 2,62 & 2,37 \\
\hline Na floricultura, utilizo equipamentos modernos. & E15 & 2,42 & 2,06 \\
\hline
\end{tabular}
Fonte: Pesquisa de campo (2018).

Observa-se uma forte desunião entre os produtores, que não organizam feiras nem participam de eventos de cunho comercial (S03; 3,69 $\pm 1,88)$, tampouco contam uns com os outros quando precisam de algum insumo emprestado para a produção (S04; 3,65 $\pm 2,24)$. Eles não compartilham mudas e novas espécies ( $\mathrm{S} 05 ; 3,50 \pm 2,21)$, nem inovações e técnicas de produção (S06; 3,27 $\pm 2,21$ ), não utilizam mecanismos modernos e eficientes para troca de informações ( $\$ 10$; $2,31 \pm 2,24)$, também não fazem compras em conjunto para aumentar seu poder de barganha ( $(\mathrm{S} 11 ; 2,12 \pm 1,82)$, da mesma forma, não atuam conjuntamente para oferecer os produtos em eventos nacionais ou internacionais ( $\mathrm{S} 12 ; 1,58 \pm 1,40)$. A fraca articulação é verificada mesmo no enfrentamento às ameaças, que se revelaram incapazes de reunir os produtores na defesa da atividade florística (S08; 2,77 \pm $1,98)$. 
Nesse contexto, a atividade não contribuiu para incrementar novas formas de organizações dos produtores (S09; 2,48 \pm 1,80), nem possibilitou que se beneficiassem das melhorias que, eventualmente, ocorreram na região, decorrentes da atividade (S07; $2,85 \pm 2,20)$, uma vez que os entrevistados não percebem melhorias no maior número de escolas, hospitais ou postos de saúde, que pudessem representar alguma conquista da categoria ( $\mathrm{S} 13 ; 1,58 \pm 1,27)$.

Tabela 3. Aspectos sociais da produção de flores e plantas ornamentais no município de Benevides (PA)

(Continua)

\begin{tabular}{l|c|c|c}
\hline Variáveis & & Média & $\begin{array}{c}\text { Desvio } \\
\text { Padrão }\end{array}$ \\
\hline $\begin{array}{l}\text { A região está muito violenta e está comprometendo minha qualidade } \\
\text { de vida. }\end{array}$ & $S 01$ & 5,08 & 2,36 \\
\hline $\begin{array}{l}\text { Meus filhos não querem trabalhar em atividades agrícolas, preferem } \\
\text { trabalhar na cidade, no futuro não sei quem irá me suceder na atividade } \\
\text { florística. }\end{array}$ & $S 02$ & 4,95 & 2,50 \\
\hline $\begin{array}{l}\text { Os floricultores do município organizam feiras e participam de eventos } \\
\text { para comercializar seus produtos junto aos consumidores locais. }\end{array}$ & $S 03$ & 3,69 & 1,88 \\
\hline $\begin{array}{l}\text { No município, os floricultores sabem que podem contar com os demais } \\
\text { quando precisam algum insumo emprestado para a produção. }\end{array}$ & $S 04$ & 3,65 & 2,24 \\
\hline $\begin{array}{l}\text { Os floricultores compartilham entre eles mudas e novas espécies. } \\
\text { Os floricultores compartilham entre eles inovações em técnicas de }\end{array}$ & $S 05$ & 3,50 & 2,21 \\
\hline $\begin{array}{l}\text { produção. } \\
\text { Os floricultores do município se beneficiam das melhorias nas condições } \\
\text { de vida locais decorrentes da plantação de flores e plantas ornamentais. }\end{array}$ & $S 07$ & 2,27 & 2,01 \\
\hline $\begin{array}{l}\text { Os floricultores do município se ajudam mutuamente sempre que } \\
\text { percebem alguma ameaça a atividade. }\end{array}$ & $S 08$ & 2,77 & 1,98 \\
\hline $\begin{array}{l}\text { A produção de flores e plantas ornamentais possibilitou novas formas de } \\
\text { organizações dos produtores no município. }\end{array}$ & $S 09$ & 2,42 & 1,80 \\
\hline $\begin{array}{l}\text { Os floricultores do município têm mecanismos tecnológicos eficientes } \\
\text { para compartilhar informações (e-mail, WhatsApp etc.). }\end{array}$ & $S 10$ & 2,31 & 2,24 \\
\hline $\begin{array}{l}\text { No município, os floricultores se organizam para fazer compras conjuntas } \\
\text { e conseguir melhores preços e condições comerciais. }\end{array}$ & $S 11$ & 2,12 & 1,82 \\
\hline
\end{tabular}


(Conclusão)

Variáveis

Média

Desvio

Padrão

Os floricultores do município atuam em conjunto para comercializar os produtos em eventos interestaduais ou internacionais.

\begin{tabular}{l|l|l} 
S12 & 1,58 & 1,40
\end{tabular}

A atividade de produção de flores e plantas ornamentais contribuiu, de alguma forma, para maior número de escolas, hospitais ou postos de saúde.

Fonte: Pesquisa de campo (2018).

A dimensão sustentabilidade mostrou a preocupação dos produtores com a preservação do meio ambiente, uma vez que, de maneira geral, as respostas se posicionaram nos estratos mais altos da escala. Assim, apesar de utilizarem adubos químicos, conforme dados apresentados na Tabela 4 , eles convergiram ao declarar que também utilizam adubos orgânicos na produção $(A 01 ; 6,69 \pm 0,62)$ na forma de compostagem $(\mathrm{A} 08 ; 5,15 \pm 2,65)$. Outra prática comum entre os entrevistados é descartar o lixo doméstico na coleta regular (A02; 6,58 \pm 0,81), evitando que seja queimado ou enterrado na propriedade. No mesmo sentido, ficou evidente que os produtores não aceitam queimadas na propriedade (A07; 5,43 $\pm 2,40)$.

Tabela 4. Aspectos ambientais da produção de flores e plantas ornamentais no município de Benevides (PA)

(Continua)

\begin{tabular}{l|c|c|c}
\hline Variáveis & & Média & $\begin{array}{c}\text { Desvio } \\
\text { Padrão }\end{array}$ \\
\hline Utilizo adubos orgânicos na produção. & $\mathrm{A} 01$ & 6,69 & 0,62 \\
\hline $\begin{array}{l}\text { O lixo doméstico produzido na minha propriedade é descartado na } \\
\text { coleta regular. }\end{array}$ & $\mathrm{A} 02$ & 6,58 & 0,81 \\
\hline $\begin{array}{l}\text { Tenho ou gostaria de ter energia solar na propriedade. } \\
\text { Evito ao máximo o uso de agrotóxicos ou defensivos agrícolas. }\end{array}$ & $\mathrm{A} 03$ & 6,53 & 1,47 \\
\hline Na minha propriedade, tenho fossa séptica. & $\mathrm{A} 04$ & 6,23 & 1,42 \\
\hline $\begin{array}{l}\text { Eu me interesso por inovações que possibilitem proteger o meio } \\
\text { ambiente. }\end{array}$ & $\mathrm{A} 06$ & 5,08 & 2,21 \\
\hline Não admito queimadas na minha propriedade. & $\mathrm{A} 07$ & 5,43 & 2,19 \\
\hline Utilizo compostagem na produção. & $\mathrm{A} 08$ & 5,15 & 2,65 \\
\hline
\end{tabular}




\begin{tabular}{|c|c|c|c|}
\hline & & \multicolumn{2}{|c|}{ (Conclusão) } \\
\hline Variáveis & & Média & $\begin{array}{l}\text { Desvio } \\
\text { Padrão }\end{array}$ \\
\hline Atendo a legislação ambiental mesmo que isso limite minha produção. & A09 & 5,12 & 2,06 \\
\hline Preservo áreas protegidas na minha propriedade. & $\mathrm{A} 10$ & 4,77 & 2,83 \\
\hline $\begin{array}{l}\text { Preservo uma parte da propriedade destinada à recuperação de áreas } \\
\text { degradadas. }\end{array}$ & A11 & 4,46 & 2,82 \\
\hline $\begin{array}{l}\text { Conservo espécies nativas para manter um banco genético de espécies } \\
\text { da região. }\end{array}$ & $\mathrm{A} 12$ & 4,31 & 2,71 \\
\hline
\end{tabular}

Fonte: Pesquisa de campo (2018).

Os produtores contam com fossas sépticas $(S 02 ; 4,95 \pm 2,50)$ e declararam que procuram evitar ao máximo a utilização de agrotóxicos ou defensivos agrícolas na produção (A04; 6,23 $\pm 1,42)$. Eles se interessam por inovações que protejam o meio ambiente $(\mathrm{S} 02 ; 4,95 \pm 2,50)$ e que utilizam ou gostariam de utilizar energia solar (S02; 4,95 $\pm 2,50)$. Os entrevistados responderam que limitariam a produção para atender a legislação ambiental (S02; 4,95 \pm 2,50) e que, mesmo com menor intensidade, eles se preocupam em preservar áreas protegidas (A10; 4,77 \pm 2,83), em destinar uma área para recuperação de áreas degradadas (S02; 4,95 \pm $2,50)$ e em manter um banco genético de espécies da região (S02; 4,95 $\pm 2,50$ ). Logicamente, essas últimas questões ficam comprometidas em propriedades com áreas muito pequenas, o que, provavelmente, contribuiu para posicionar as médias mais próximas ao centro da escala.

Os resultados dessa seção mostraram que a produção de flores e de plantas ornamentais em Benevides é uma atividade financeiramente necessária para a composição da renda dos entrevistados. Contudo, revela uma contribuição muito restrita em sua capacidade de contribuir para o desenvolvimento, uma vez que não consegue proporcionar acumulação de patrimônio, nem possibilita alguma diversificação ou maior expansão nos negócios, aspectos que poderiam levar a um maior dinamismo econômico na região. Desta forma, como destaca Sachs (2004) o aspecto econômico é conditio sine qua non para que ocorra desenvolvimento.

Uma hipótese para a limitada contribuição econômica da atividade pode se fundamentar em Landini (2015), que destaca que os produtores rurais carecem de uma visão mais empresarial, pois "eles não veem sua propriedade como uma 
empresa" (p. 375), em contrapartida, os resultados mostraram alguma contribuição na formação de capital humano pelo aprendizado, tanto técnico, quanto gerencial (E03), mas esse aspecto se revelou limitado.

$\mathrm{Na}$ dimensão social, as limitações observadas na atividade foram ainda mais evidentes, pois os entrevistados se mostraram desinteressados em atuar coletivamente pelo que desejam, eles adotam um comportamento isolado, sem interesse ou disposição de trabalhar em conjunto, mostrando, assim, uma limitação de capital social, aspecto que, conforme Kronemberger (2011), é uma condição necessária ao desenvolvimento, visto que, como evidencia a autora, pode haver capital social sem desenvolvimento, mas não há desenvolvimento sem capital social. Achados de atuação desarticulada de produtores também estão presentes na investigação de Ribeiro, Lírio e Ferreira (2014), ao pesquisarem floricultores mineiros, que, assim como os entrevistados de Benevides, optam por uma atuação atomizada.

A perspectiva ambiental foi a que revelou a maior disposição dos produtores, que manifestaram vontade de preservar o meio ambiente. Mitsueda, Costa e D'Oliveira (2011, p. 12) destacam que a "região norte do Brasil apresenta o maior potencial de expansão da floricultura" e complementam ao afirmar que a produção de flores e plantas ornamentais não está imune aos impactos ambientais, entretanto, quando comparadas com outras culturas, esses impactos são menores. Nesse sentido, os entrevistados evidenciaram que colocariam a preservação do meio ambiente como prioridade com relação aos aspectos financeiros e, assim, reforçaram a dimensão ambiental da produção, essencialmente voltada para a sustentabilidade ambiental.

\section{CONSIDERAÇÕES FINAIS}

O objetivo da pesquisa foi analisar a agricultura de flores e plantas ornamentais na perspectiva do desenvolvimento local no município de Benevides, Estado do Pará. A atividade não conta com estatísticas quanto à produção do setor, sendo as informações divulgadas aproximações dos técnicos que atuam na região. Não há um cadastro atualizado que dê conta da atividade, nem na secretaria, nem na prefeitura, nem na empresa de assistência técnica do Estado. Como os produtos 
são isentos de tributação, acredita-se que a maior parte da negociação ocorra sem documentação fiscal, aspecto que limita ainda mais as estatísticas da produção e comercialização.

Os produtores são essencialmente desarticulados, as associações que já existiram não conseguiram se firmar, estando, atualmente, completamente atomizados e, provavelmente, ainda mais isolados do que no passado. Os resultados mostram pouco ou quase nenhum capital social entre os produtores que, praticamente, não têm nenhuma ação conjunta organizada além das eventuais relações de amizade, que ainda propiciam algumas ações esporádicas. As relações dos produtores com as instituições públicas são ruins, mas as relações comerciais são um ponto forte do setor, pois os produtores se relacionam muito bem com clientes e fornecedores. Comercialmente, praticamente toda a produção é destinada ao mercado local, assim como observado em outras investigações, estando bem alinhada com as teorias estudadas.

A localização em Benevides mostrou ser um aspecto positivo para o cultivo de flores e plantas ornamentais, mas os produtores não creditam à atividade florística nenhuma conquista de melhoria local em relação a hospitais, escolas, estradas, entre outros, indicando que a atividade praticamente não conquista benefícios que promovam a qualidade de vida no município. Os produtores têm facilidade de acesso ao crédito para a produção e sabem que podem lucrar com a atividade, entretanto não se mostraram abertos para contrair dívidas para a atividade florística, por considerarem que as linhas de crédito existentes não são adequadas para a atividade.

Desta forma, a pesquisa identificou, salvo raras exceções, uma atividade de subsistência, com expressivas limitações em contribuir para o desenvolvimento na forma como é praticada atualmente. O capital social é baixo e, apesar de a dimensão ambiental se mostrar um ponto positivo da atividade, como a maioria dos produtores tem áreas muito pequenas, não conseguem alavancar a produção para gerar efeitos que possam se espalhar pela economia, o que resulta em pouca ou nenhuma contribuição para o desenvolvimento local.

Merece destaque a necessidade da iniciativa nesse processo vinda especialmente de instituições do âmbito federal, estadual e municipal, por meio de 
ações planejadas, nas quais deve caber ao Estado desenvolver estratégias de ordem tecnológica, social e comercial, uma vez que a atividade é de baixo impacto ambientale conta com a possibilidade de explorar mercadologicamente a perspectiva amazônica para uma produção voltada à agroecologia e, assim, trazer uma contribuição mais efetiva e duradoura para o desenvolvimento na região.

\section{REFERÊNCIAS}

BUARQUE, S. C. Construindo o desenvolvimento local sustentável: metodologia de planejamento. Rio de Janeiro: Garamond, 2008.

CONFEDERAÇÃO DA AGRICULTURA E PECUÁRIA DO BRASIL. Seminário de comércio exterior sobre flores 2017. Disponível em: http://www.cnabrasil.org.br/ seminario-de-comercio-exterior-sobre-flores-palestras. Acesso em: 25 jun. 2017.

COUTINHO, M. N.; COSTA, H. S. M. Agricultura urbana: prática espontânea, política pública e transformação de saberes rurais na cidade. Geografias, v. 7, n. 2, p. 81-97, jul./dez. 2011.

GOVERNO DO ESTADO DO PARÁ. Estatísticas municipais paraenses: Benevides. Belém: FAPESPA, 2016. Disponível em: http://www.fapespa.pa.gov.br/upload/ Arquivo/anexo/1302.pdf?id=1502808203. Acesso em: 5 ago. 2017.

FREITAS, H. R.; GONÇALVES-GERVÁSIO, R. C. R.; MARINHO, C. M.; FONSECA, A. S. S.; QUIRINO, A. K. R.; NASCIMENTO, P. V. P. Horta escolar agroecológica como instrumento de educação ambiental e alimentar na Creche Municipal Dr. Washington Barros - Petrolina/PE. Extramuros, v. 1, n. 1, p. 155-169, jan./jun. 2013.

GHISLENI, G. A. Associação de agricultores periurbanos: uma alternativa de desenvolvimento local na Região Missioneira do Rio Grande do Sul. 2012. $71 \mathrm{f}$. Dissertação (Mestrado em Desenvolvimento) - Universidade Regional do Noroeste do Estado do Rio Grande do Sul, Ijuí, 2012.

GIL, A. C. Métodos e técnicas de pesquisa social. São Paulo: Atlas, 2014. 
IBGE. Censo demográfico 2010. 2010. Disponível em: https://ww2.ibge.gov.br/ home/estatistica/populacao/censo2010/default.shtm. Acesso em: 7 jul. 2017.

IBGE. Brasil / Pará / Benevides. Disponível em: http://cidades.ibge.gov.br/xtras/ perfil.php?codmun=150150. Acesso em: 5 jul. 2017.

INSTITUTO BRASILEIRO DE FLORICULTURA. Informativo Ibraflor 2017. Disponível em: http://www.holambra.sp.gov.br/cidade.html. Acesso em: 31 jun. 2017.

JUNQUEIRA, A. H.; PEETZ, M. S. Perfil da cadeia produtiva de flores e plantas ornamentais da Mesorregião Metropolitana de Belém (PA). Belém: SEBRAE, 2006.

KRONEMBERGER, D. Desenvolvimento sustentável: uma abordagem prática. São Paulo: Senac, 2011.

LANDINI, F. P. Problemas enfrentados por extensionistas brasileiros e sua relação com suas concepções de extensão rural. Ciência Rural, v. 45, n. 2, p. 371-377, fev. 2015.

MADALENO, I. M. A cidade das mangueiras: agricultura urbana em Belém do Pará. Lisboa: Fundação Calouste Gulbekian, Fundação para a Ciência e a Tecnologia, 2001.

MARTINELLI, D. P.; JOYAL, A. Desenvolvimento local e o papel das pequenas e médias empresas. São Paulo: Manole, 2004.

MITSUEDA, N. C.; COSTA, E. V.; D’OLIVEIRA, P. S. Aspectos ambientais do agronegócio flores e plantas ornamentais. Revista em Agronegócio e Meio Ambiente, $\mathrm{v}$. 4, n. 1, p. 9-20, jan./abr. 2011.

MONTEIRO, J. P. R.; MONTEIRO, M. S. L. Hortas comunitárias de Teresina: agricultura urbana e perspectivas de desenvolvimento local. Revista Iberoamericana de Economia Ecológica, v. 5, p. 47-60, dec. 2006.

MOUGEOT, L. J. A. Agricultura urbana: concepto y definicón. La Revista Agricultura Urbana, v. 1, jul. 2000. 
NEVES, M. F.; PINTO, M. J. P. (coord.) Mapeamento e quantificação da cadeia de flores e plantas ornamentais no Brasil. São Paulo: OCESP, 2015.

PESSÔA, C. C. Agricultura urbana e pobreza: um estudo no município de Santa Maria - RS. 2005. 86 f. Dissertação (Mestrado do Programa de Pós-Graduação em Extensão Rural) - Universidade Federal de Santa Maria, Santa Maria, 2005.

RIBEIRO, I. M. D.; LÍRIO, V. S.; FERREIRA, A. M. S. Caracterização do segmento de plantas ornamentais de Teófilo Otoni - MG: produção e comercialização. Revista Econômica do Nordeste, Fortaleza, v. 45, n. 4, p. 121-135, out./dez. 2014.

RIBEIRO, S. M.; AZEVEDO, E.; PELICIONI, M. C. F.; BÓGUS, C. M.; PEREIRA, I. M. T. Agricultura urbana agroecológica: estratégia de promoção da saúde e segurança alimentar nutricional. Revista Brasileira de Promoção da Saúde, v. 25, n. 3, p. 381-388 jul./set. 2012.

SACHS, I. Desenvolvimento includente, sustentável e sustentado. Rio de Janeiro: Garamond, 2004.

SANTOS, D. H. Agricultura urbana e segurança alimentar. Revista Saber Acadêmico, n. 11, p. 172-182, jun. 2011.

SEBRAE. Flores e plantas ornamentais: série estudos mercadológicos. 2015. Disponível em: http://www.bibliotecas.sebrae.com.br/chronus/ARQUIVOS_CHRONUS/ bds/bds.nsf/560c96e3b1583358357b7b6a59e460a7/\$File/5517.pdf. Acesso em: 25 maio 2017.

SILVA, J. K. L.; SOUZA, M. P.; MENEGUETTI, N. F. S. P.; MACIEL, L. A. P.; ASSUNÇãO, A. Políticas públicas e a gestão de empreendimento periurbano de agricultura familiar em Pontes e Lacerda-MT. Revista Científica da Faculdade de Educação e Meio Ambiente, v. 4, n. 1, p. 89-105, jan.jun. 2013.

SILVESTRE, A. L. Análise de dados e estatística descritiva. Lisboa: Editora Escolar, 2007.

TROIAN, A.; DALCIN, D.; OLIVEIRA, S. V.; TROIAN, A. Jovens e a tomada de decisão entre permanecer ou sair do meio rural: um estudo de caso. Revista de Extensão 
e Estudos Rurais, v. 1, n. 2, p. 349-374, jul./dez. 2011.

VÁZQUEZ BARQUERO, A. Desenvolvimento econômico endógeno em tempos de globalização. Rio Grande do Sul: Ed. da UFRGS, 2000.

VINHOLI, A. C.; MARTINS, P. Agricultura urbana e êxodo rural. Revista de Ciências Sociais, Fortaleza, v. 43, n. 1, p. 66-79, jan.jun. 2012.

Recebido em:14/04/2018

Aceito em:28/08/2018 